\title{
Conhecimento tradicional Kaingang: o uso de ervas medicinais ${ }^{1}$
}

\author{
Jéssica Gaudêncio? ${ }^{2 i D}$
}

Universidade de Coimbra

Sérgio Paulo Jorge Rodrigues ${ }^{3}$

Universidade de Coimbra

Décio Ruivo Martins4 (iD)

Universidade de Coimbra

Rosemari Monteiro Castilho Foggiatto Silveira 5 (D)

Universidade Tecnológica Federal do Paraná

Dossiê | Dossier | Dosier

DOI do artigo: 10.22481/odeere.v6i2.9793

RESUMO

O povo Kaingang é o mais populoso do Sul do Brasil e está entre os mais numerosos povos indígenas do país. Neste trabalho faz-se uma relação entre as informações encontradas na literatura e a atualidade na Terra Indígena Kaingang em relação ao conhecimento que possuem sobre o uso de plantas para a cura de doenças e como interpretam a ação da erva no organismo. Para isto, realizou-se uma pesquisa de campo em uma Terra Indígena Kaingang no Paraná, cujo entrevistas forneceram confirmações históricas em relação aos etnoconhecimentos da etnia, da evolução dos aspectos químicos e das atitudes perante a química e os remédios de origem farmacêutica e natural.

Palavras-chave: Kaingang, ervas medicinais, etnociência.

\section{Kaingang traditional knowledge: the use of medicinal herbs}

\begin{abstract}
The Kaingang people are the most populous in southern Brazil and are among the most numerous indigenous people of the country. In this work, a relationship is made between the information found in the literature and Kaingang's current situation in relation to their knowledge about the use of plants to cure diseases and how they interpret the action of the herb in the body. For this, field research was carried out in a Kaingang village in Paraná, whose interviews provided historical confirmations in relation to the ethnoknowledge of ethnicity, the evolution of chemical aspects and attitudes towards chemistry and medicines of pharmaceutical and natural origin.
\end{abstract}

Keywords: Kaingang, medicinal herbs, ethnoscience.

\section{Submetido em: 30/10/2021 | Aceito em: 24/11/2021}

\footnotetext{
1 Este trabalho foi apoiado por fundos nacionais da FCT - Fundação para a Ciência e a Tecnologia, I.P., inserido no projeto UID/04564/2020 e realizado com apoio da Coordenação de Aperfeiçoamento de Pessoal de Nível Superior - Brasil (CAPES) - Código de Financiamento 001.

2 Doutoranda em História das Ciências e Educação Científica, Centro de Física da Universidade de Coimbra, Portugal (CEFisUC) em cotutela com o Programa de Pós-Graduação em Ensino de Ciências e Tecnologia (PPGECT), Universidade Tecnológica Federal do Paraná (UTFPR), Campus Ponta Grossa, Paraná, Brasil. E-mail: jessigaudencio@hotmail.com

3 Professor Doutor no Departamento de Química da Universidade de Coimbra (UC) - Portugal. Email: spjrodrigues@ci.uc.pt

4 Professor Doutor no Departamento de Física da Universidade de Coimbra, Portugal. Doutor em História e Ensino da Física, Centro de Física da Universidade de Coimbra, Portugal (CEFisUC). E-mail: decio.r.martins@gmail.com

5 Professora Doutora no Programa de Pós-Graduação em Ensino de Ciências e Tecnologia (PPGECT), Universidade Tecnológica Federal do Paraná (UTFPR), Campus Ponta Grossa, Paraná, Brasil. Doutora em Educação Científica e Tecnológica. E-mail: foggiattorm@hotmail.com
} 


\section{Introdução}

A cultura indígena brasileira é frequentemente estudada por diversas áreas e pesquisadores interessados nos diversos saberes e conhecimentos empíricos, nos seus costumes e tradições. Contudo, grande parte volta-se para as populações indígenas das regiões Norte e Centro-Oeste brasileiras, pois lá concentram-se ainda diversas etnias indígenas que vivenciam seus costumes integralmente ou que não sofreram com a aculturação, além das tribos que ainda existem isoladas na floresta amazônica. Mas, as etnias indígenas das demais regiões do Brasil também devem continuar sendo pesquisadas e investigadas, pois mesmo que apresentem uma sociedade inserida nos costumes regionais e se relacionem com os não-índios, ainda preservam suas culturas e utilizam seus conhecimentos em suas atividades diárias diversas.

O povo Kaingang é o mais populoso do Sul do Brasil e está entre os mais numerosos povos indígenas do país. Esta etnia indígena pertence à família linguística Jê, do tronco Macro-Jê e estima-se uma população de 45.620 pessoas a viver em mais de 40 Terras Indígenas, conforme o Sistema de Informação da Atenção à Saúde Indígena (GAUDÊNCIO et al., 2019). Estudos realizados por pesquisadores como Moacir Haverroth (1997), Eduardo Andrade (2013) e Deyvylan Reis (2016) revelam aspectos etnográficos importantes desta etnia, como amplo domínio vegetal com sistema próprio de classificação das plantas, utilizando-as para diversos fins medicinais juntamente com práticas rituais que fornecem os poderes da natureza. Para o poder da cura e prevenção de diversos tipos de doenças, os curadores e os xamã fazem o uso das ervas e plantas do mato, em que possuem um esquema particular de organizar cognitivamente essas plantas, originalmente aprendida com seus ancestrais e que ainda hoje são tradicionalmente repassados, de geração em geração (GAUDÊNCIO et al., 2020).

Diante desse contexto, esse artigo tem como objetivo buscar informações referentes a atualidade da etnia indígena Kaingang analisadas conforme pesquisa histórica encontrada na literatura. Para isso realizou-se uma pesquisa de campo em uma das Terras Indígenas Kaingang localizada no Estado do Paraná. Este artigo apresentará informações a respeito da cultura Kaingang na atualidade, mas também confirmações históricas baseadas na memória dos indivíduos em relação aos etnoconhecimentos da etnia e das atitudes perante a química e os remédios de origem farmacêutica e natural. 


\section{Entrevistas com indígenas Kaingang}

Realizou-se a pesquisa de campo em uma Terra Indígena localizada no Estado do Paraná. Para isso, obteve-se licença junto à FUNAI para a realização da entrada em Terra Indígena e parecer liberado pelo Cep (Comitê de Ética em Pesquisa) e Conep (Comissão Nacional de Ética em Pesquisa) para pesquisa com populações indígenas, com os dados CAAE: 28499420.9.0000.5547; Número do Parecer: 4.149.281. Utilizou-se o procedimento de estudo de caso com técnicas de observação e entrevistas, sendo a pesquisa de campo baseada na observação de fatos e fenômenos espontâneos in loco. Nove indivíduos pertencentes a etnia indígena Kaingang foram entrevistados e seus nomes foram alterados para a sua não identificação. As entrevistas foram semiestruturadas, na qual se estabeleceu uma direção geral para a conversação, seguindo tópicos específicos, apresentando entrevistas flexíveis e não-estruturadas, que correspondem a conversações livres sobre o tema e ao interesse da pesquisa (FONSECA, 2002). Assim, a abordagem metodológica é qualitativa, de natureza interpretativa a partir de observação. A análise das entrevistas foi realizada seguindo as orientações de Moreira e Caleffe (2008) e apoiada na análise de conteúdo de Bardin (1977) para descrição das categorias emergentes.

Assim, foi possível designar quatro categorias: 1) Conhecimento em relação ao uso de plantas para a cura de doenças; 2) Percepções Kaingang sobre 0 conhecimento científico; 3) Interpretação da ação da erva no organismo e 4) Plantas medicinais mais citadas entre os entrevistados. Para a transcrição das narrativas nas entrevistas utilizou-se o quadro de legendas de Myers (2002) com adaptações de Azevedo et al. (2017), como pode ser observado no Quadro 1 a seguir:

Quadro 1: Conversões de transcrição' para entrevistas (adaptado de MYERS, 2002; AZEVEDO et al., 2017)

\begin{tabular}{|c|c|}
\hline \multicolumn{2}{|c|}{$\begin{array}{c}\text { LEGENDA PARA TRANSCRIÇÃO DE ÁUDIO } \\
\text { conversões de transcrição }\end{array}$} \\
\hline Sublinhado & ênfase \\
\hline$/$ & o começo de falas sobrepostas \\
\hline 1 & pausa curta \\
\hline$(2.0)$ & pausa longa \\
\hline$==$ & continuações sem pausas audiveis \\
\hline
\end{tabular}

\footnotetext{
6 As transcrições foram realizadas conforme a fala dos indivíduos, sendo boa parte utilizada a transcrição literal. Portanto, as falas podem não apresentar concordâncias verbais corretas, assim como palavras no singular e no plural.
} 


\begin{tabular}{|c|c|}
\hline$[$ ] & transcrição incerta \\
\hline$[\ldots]$ & silêncios/pausas/conversas aleatórias \\
\hline ( ) & informação adicional entre parêntesis \\
\hline
\end{tabular}

\section{Conhecimento em relação ao uso de plantas para a cura de doenças}

Sobre o conhecimento e interesse dos indígenas entrevistados na utilização de plantas e ervas para a cura de doenças, inicialmente perguntou-se se eles ainda utilizam remédios do mato ou dão preferência aos remédios da farmácia. A seguir encontram- se alguns trechos das respostas obtidas:

MA - motorista, 50 anos: "depende da doença . a gente vai primeiro no mato .e depois na farmácia. que nem chá pra gripe dificilmente a gente vai na farmácia ou procura o postinho de saúde. gripe. febre . essas coisas . alguma dor de estômago mais é chá".

"[...] agora bem dizer a gente usa mais da farmácia (remédio) mas a gente não deixa usar ainda os remédios tradicionais tanto pra gente, que nem aqui pra gente [...] que tem bastante cachorro [...] às vezes o cachorro se corta tem remédio que a gente faz pra eles e até pra gente. não deixamos ainda, não abandonamos as ervas (2.0) os meus pais usavam muito (ervas)".

EC - pedagoga, $\mathbf{5 0}$ anos: "(meus pais usavam erva) e ensinaram (seus conhecimentos) porque a partir do momento que a gente montou a família da gente, então daí a gente já sabia quais os remédios usar né pras crianças que a gente ia tendo, então a gente aprendeu com os pais e daí agora ensina para os filhos né".

RC - costureira, 58 anos: "eu vejo assim que [...] vão mais no médico (as pessoas da aldeia) fazem exame tomam remédio pro coração, infecção urinária . porque daí faz alívio mais rápido . se você tomar agora meio dia você já tá melhor . [então muitos não procuram mais remédio do mato] [...] mas nós aqui tomamos".

JT - posição de destaque na aldeia, 52 anos: "utilizamos (ervas e plantas) a maioria (das pessoas) aqui sim [...] eu uso do mato [...] mais do mato, da farmácia assim não $==$ é pouco que tomo. porque você vai você pega uma receita e eles receitam né . e daí você é obrigado a pegar o remédio né, mas eu uso mais o do mato (2.0) (esses ensinamentos sobre ervas) eu aprendi dos meus avós".

MS - curandeira, 81 anos: "essas remediaria do mato e de casa tem de montão . tomamos remédio do mato tomamos remédio de casa . bebemos de tudo [...] e da farmácia nós bebemos também [...] bebemos tudo junto".

NC - curandeiro, 46 anos: "(quando eu tenho uma doença) eu primeiro procuro o do mato [...] daí aguardo uns três dias, dois dias pra ver se vai fazer o efeito . a gente sente né . se vai fazer o efeito . daí a gente continua ali . daí não vai na farmácia [...] talvez se ainda a doença tá meia agitada pro corpo da gente [...] [daí a gente vai lá pro postinho (posto de saúde local) se queixar das == pedir os remédio, contar o que a gente tá passando]".

MA - curandeira, 71 anos: "eu uso, tem bastante remédio do mato [...] (prefiro usar remédio do mato do que da farmácia) porque o do mato é melhor vou ali pego um punhado do chá lá fervo ali e (†omo) [...] amanhã eu tô boa . o da farmácia você fica tomando, tomando, tomando . o que eu tomo da farmácia sabe o que é . só remédio pra pressão . porque eu não achei o remédio do mato . mas dizem que tem remédio do mato (para pressão alta) [...] eu vou (procurar) . mas eu não posso andar mais . esse aí que é o problema [...]". 
No geral, todos ainda utilizam os remédios do mato, sendo constatado uso frequente de remédios da farmácia para doenças crônicas como hipertensão e diabetes (medicamentos controlados). Para dores de cabeça, estômago, gripe e doenças com sintomas mais leves, os entrevistados utilizam os remédios do mato, os quais alguns foram citados em algumas passagens:

RC - costureira, 58 anos: "na época eles (pais) usavam pra curar mais com puxamento de erva, banho de erva . tomar os chás de erva . de cipó . [...] nós temos até aqui um cipó que nós usamos . era pra bichas, pra vermes assim né que eles diziam tá atacado das bichas né . mas era vermes 7 . até pra derrubar vermes eles tinham (ervas) ${ }^{8}$ (2.0) tem o cipó milome, tem o cipó de escada para a coluna [...] nós tomamos ainda, no chimarrão9 . aí quando a gente tá com muita dor nós fazemos pra nós tomar [...] hoje já os mais novos não usam mais [...]".

JS - posição de destaque na aldeia, 63 anos: "eu acho assim que . nós indígena que nem . quase todos os indígenas . eles dependem da mata [...] pra vermes . daí a minha mãe fazia pra mim [...] o chá do milome e o hortelã [...] só que tem hortelã branco e o hortelã roxo né . mas ela fazia do hortelã roxo pra eu tomar. e eu tomava . e derrubava vermes né [...] tem o caraguatá que dá no gramado né . que é muito bom pra câncer também == casca de ipê [...] volte e meia ela (esposa) faz chá pras pessoas [...] ela fez esses dias para a comadre dela que tava com o coração inchado ela fez também . remédio . e a comadre dela melhorou". MA - motorista, 50 anos: "[...] tem alguns cipós [...] até a gente que se corta né se tem algum cipó ali que é mole você esmaga ele e põe uma água ali e lava o machucado ali . depois que você lava com esse cipó você pega a taquara . queima a taquara e daí aquele carvão preto você mói ele faz um pozinho você passa ele em cima e já seca [...]".

"[...] pedra na vesícula, no rim . pedra na vesícula eu não fui preciso operar . eu tive pedra na vesícula desse tamanho . daí eu tomei o remédio . o doutor falar pra mim que não existe remédio que desmanche pedra na vesícula que derrube né . daí ele fez outra ultrassom . não tinha mais né [...] de dez pessoas que tavam já com a cirurgia marcada, oito não fizeram cirurgia [...] tomando os medicamentos (do mato) [...] que nem olha essa guavirovera ali . é uma guavirova [...] ela é uma árvore nativa né, uma fruta nativa [...] a guavirova sozinha é pra diarreia né . mas ela junto com tarumã, ela, pra alguns assim combate a diabetes [...] e tem vários outros né (2.0) os pais e os avós (que ensinaram sobre ervas) e vamos aprendendo (2.0) tem um capim aí que dá numa caxopla é pra regular a pressão . pressão alta . qualquer pressão tanto a alta como a baixa . então ela normaliza".

EC - pedagoga, 50 anos: "tem o cipó escada que é pra coluna né [...] quando destronca né assim ou quebra que eles engessam é assim [...] tem até pra depressão né que é o cipó de São João . é uma arvorezinha . ela não dá bem uma árvore [...] o único lugar que a gente acha é pra lá, perto do lajeado . então a folha dela é pra depressão e a raiz para diabetes".

JT - posição de destaque na aldeia, 52 anos: "[...] que nem quebradura né é mais

\footnotetext{
7 Bichas, vermes: termo popular para parasitas intestinais.

8 Omitiu o nome das ervas.

9 Bebida característica do Sul do Brasil composta por erva-mate e água.
} 
curado com remédio do mato. dependendo da quebradura que você tem . por exemplo você vai no médico . o médico engessa. daí você vai tirar o gesso . você quer que cicatrize mais logo ou firme já teu osso já digo né . é remédio do mato [...] nós chamamos aqui de grupieiro . o grupieiro você corta a madeira e daí você queima ele faz o carvão e bate com banha de porco bem batido . e você passa na tua quebradura ele vai colar e você vai ficar perfeito".

O estudo de Deyvylan Reis (2016) mostra que dentre os variados remédios caseiros para o tratamento de doenças crônicas, o uso de ervas e plantas mais comuns entre os indígenas Kaingang são:

[...] água com alho, chá da casca da laranja, uso de garrafada, chá de boldo, chá de erva cidreira, chá de jucá, amora, berinjela; chá de pau de tenente; chá de nani; chá de berinjela; chá de quebra-velho e amor crescido; chá de capim-santo e pau do mato; água com pepino e berinjela; banho de arruda; chá da folha da azeitona; chá da folha de sara tudo; chá da folha de insulina; chá de capim-santo; chá de cuia; chá da folha de abacate; chá de jambu; copaíba; chá da folha de tangerina; e chá de canela (REIS, 2016, p. 120).

Confirma-se que alguns costumes ainda estão presentes na realidade da etnia, como as garrafadas citadas por Reis (2016), com combinações de ervas, raízes, folhas e cascas. Em relação às plantas mais comuns usadas pela etnia Kaingang, a folha do abacate e o pau amargo foram mencionadas:

MA - curandeira, 71 anos: "pau amargo (pra estômago) é bom demais, eu tomava pra pedra da vesícula [...]".

MK, acadêmica de enfermagem, 38 anos: "eu uso (ervas) . bastante [...] quando eu fico assim com dor . que nem quando ataca assim meus rins . eu uso a folha de abacate [...] daí eu não vou consultar, eu só tomo em casa, melhoro, daí não vou consultar [...] aí da aroeira que descobri que é bom também pra dor né . é antiinflamatório [...] a aroeira é um bom remédio [...] a folha do abacate é antiinflamatório . eu tenho problema nos meus rins. eu não vou no postinho (posto de saúde) quase . eu faço o chá em casa . eu me curo com aquilo lá . [...] então eu vou ali (no mato) tiro e fervo e tomo [...] aroeira é bom até pra bexiga [...] a gente vai descobrindo aqui dentro aos poucos também [...] tem a aroeira, a folha de abacate . tem essa espinheira santa [...] tem um monte de ervas".

Sobre a planta sete-sangrias (Cuphea carthagenensis), muito referida na literatura Kaingang por ser utilizada na pintura corporal tradicional e para dores de estômago por suas propriedades diuréticas, laxativas e diaforéticas, a entrevistada RC do grupo 2 fez menção a essa planta nas suas duas funções, tanto na pintura quanto para tratamento de doenças. A RC explicou que existem vários tipos da planta chamada sete sangrias, a que dá uma espécie de frutinha que é utilizada para obter corante e outra que utilizam as folhas para fazer chá no combate do 
diabetes:

RC - costureira, 58 anos: "nós usamos (sete sangrias) porque ele (esposo) tinha diabetes né, tinha colesterol [...] mas não é a mesma [...] tem uma sete sangrias te quem uma frutinha pra fazer pintura [...] mas daí tem de outros tipos né [...] aí ele tomou e sarou da diabetes".

Andrade (2013) registrou em Terras Indígenas Kaingang Apucarana que a maioria dos remédios utilizados por eles são do mato, a partir das plantas, porém existem remédios provenientes de animais e de objetos (pedra ou areia, por exemplo) que para os Kaingang possuem espíritos com ações de intencionalidade. Assim, perguntou-se aos entrevistados sobre essas interpretações visuais da natureza e se ainda as utilizam para curar doenças ou combatê-las. Nesse sentido, apenas um dos entrevistados fez menção ao uso de pedras e madeiras para este fim:

NC - curandeiro, 46 anos: "já ouvi (falar no uso de pedra e madeira para cura) tem uma pedrinha, só que dessa pedrinha é pra doença pros cães né [...] se eles estão com peste, de sangue vamos dizer, eu vou lá naquela serra lá, e vejo lá e raspo [...] e venho e dou para eles e eles saram também [...] tem uma madeira por nome pau amarga [...] aquele é muito amarga, aquele também é bom, é bom pra peste de cachorro [...] raspa ele e cozinha e . dá para ele beber".

Sobre a pesquisa de Haverroth (1997) da qual relaciona um esquema de classificação ou catalogação Kaingang para plantas de uso medicinal, não foi constatado nenhum tipo de classificação por partes dos entrevistados. Das três formas de classificação identificadas por Haverroth, morfoecológica, utilitária e simbólica, pôde-se considerar a primeira delas nas falas dos entrevistados, a morfoecológica, em que existe a identificação da planta a partir da nomenclatura fornecida pelo indígena juntamente com informações adicionais sobre o seu domínio vegetal. As outras duas classificações não foram identificadas, mas pode ser devido as perguntas serem mais superficiais e não tão específicas como deveriam ser para uma pesquisa analítica relacionada a botânica, com identificação e classificação de espécies por exemplo, mas esse não é o objetivo.

\section{Percepções Kaingang sobre o conhecimento científico}

De forma sucinta, analisou-se qual a percepção que os entrevistados têm em relação ao conhecimento científico e como relacionam as palavras ciências e/ou química. Ao longo da conversa na entrevista, percebeu-se que em 
determinados momentos, falas deram indicativos de um conhecimento mesmo que superficial sobre ciências. A palavra química é muito relacionada à remédio de farmácia (comprimido/cápsulas):

RC - costureira, $\mathbf{5 8}$ anos: "na época era mais usado esses (ervas do mato) . às vezes a gente fica comentando que (2.0) naquela época quase não tinha quase é . química né . esses remédio de farmácia, não tinha médico . mas era os chamoios . os pajés . os kujà né . da aldeia".

MA - curandeira, 71 anos: "nunca ouvi falar em ciência e química".

JT - posição de destaque na aldeia, 52 anos: "já ouvi falar (em ciência e química) . sabe que nunca falei disso com meus filhos".

A entrevistada RC mencionou sobre o efeito dos remédios do mato e da farmácia, considerando que os da farmácia promovem o alívio das dores, mas não a cura como os remédios do mato:

RC - costureira, $\mathbf{5 8}$ anos: "parece que a química faz efeito mais rápido né . e o natural demora um pouco mais. só porque ele age de forma . assim que ele é mais pra cura né . e o rápido é mais pra aliviar a dor e ali um pouco tá de novo".

O entrevistado NC, curandeiro, questiona sobre o remédio que está na farmácia ser fabricado a partir do remédio do mato:

NC - curandeiro, 46 anos: "sim (já ouvi falar em ciência e química) . de remédio, mas ele faz muito bem pra saúde das pessoas, ele ajuda grande a gente, ajuda bastante e protege a gente também. esse remédio do mato protege bastante a gente . tanto do mato quanto (da farmácia) porque acho que esse remédio que tem (na farmácia) também . vem do mato . eles fazem do mato".

Mostrou-se para os entrevistados algumas fórmulas químicas que representam substâncias comuns, como a água $\left(\mathrm{H}_{2} \mathrm{O}\right)$, o sal de cozinha $(\mathrm{NaCl})$ e o gás carbônico $\left(\mathrm{CO}_{2}\right)$. O Quadro 2 indica que somente dois entrevistados souberam - que representavam as fórmulas químicas apresentadas e somente um reconheceu a fórmula da água especificamente. Os demais olharam os símbolos químicos e disseram que não lembravam de nada, nem viram na TV e que não conseguiram correlacionar com nada existente em suas memórias.

Quadro 2: Relação dos entrevistados e o reconhecimento das fórmulas químicas

\begin{tabular}{|c|c|c|c|}
\hline Entrevistado & $\mathrm{CO}_{2}$ & $\mathrm{NaCl}$ & $\mathrm{H}_{2} \mathrm{O}$ \\
\hline $1 \mathrm{EC}$ & $\operatorname{sim}$ & $\operatorname{sim}$ & $\operatorname{sim}$ \\
\hline $1 M K$ & $\operatorname{sim}$ & $\operatorname{sim}$ & $\operatorname{sim}$ \\
\hline $1 M A$ & não & não & sim \\
\hline $2 \mathrm{JS}$ & não & não & não \\
\hline $2 R C$ & não & não & não \\
\hline
\end{tabular}




\begin{tabular}{|c|c|c|c|}
\hline 2JT & não & não & não \\
\hline $3 N C$ & não & não & não \\
\hline $3 M A$ & não & não & não \\
\hline $3 M S$ & não & não & não \\
\hline
\end{tabular}

As duas pessoas que identificaram a representação das fórmulas químicas possuem ensino superior. As demais possuem pouca escolarização, podendo se fazer a interpretação de que quando se deparam com representações científicas (em TV, livros, revistas, internet) não as compreendem e nem fazem correlações com demais atividades do cotidiano.

De acordo com Cunha (2009) e Lévi-Strauss (1989), o conhecimento tradicional apresenta condições necessárias para a sua existência, uma delas é a relação que deve existir entre a comunidade, em que os saberes e objetos são trocados livremente, cooperando com o conhecimento coletivo. A ciência moderna usa conceitos e a ciência tradicional usa percepções, enquanto a ciência percorreu por grandes conquistas tecnológicas e científicas, a tradicional também obteve êxito em descobertas e invenções notáveis percorridas pela lógica das percepções, do sensível, cujo fundamento não entendemos completamente.

Assim, muitos conhecimentos trazidos por indígenas e outras comunidades tradicionais despertam interesse por pesquisadores das mais variadas áreas. Muitas vezes a ciência tradicional é diminuída, um exemplo, segundo Cunha (2009), é dizer que ela não procede por invenção, somente por descoberta, ou até mesmo por imitação de primatas que usam ervas medicinais. O fato de os entrevistados não compreenderem a ciência, ou não identificarem símbolos científicos não exclui possibilidades de desenvolverem técnicas e conhecimentos a respeito da natureza. O conhecimento tradicional tem um grande potencial de renovação de seus próprios paradigmas, saber observar e compreender os conceitos envolvidos em suas práticas podem facilitar e orientar o processo da ciência. No caso da medicina popular, isso pode ser útil na gênese de verdadeira inovação para o desenvolvimento de medicamentos, por exemplo. Porém, não basta apenas fazer a validação dos resultados tradicionais pela ciência contemporânea, mas fazer o reconhecimento de que as práticas das ciências tradicionais são fontes potenciais de inovação para a ciência moderna (CUNHA, 2009). 


\section{Interpretação da ação da erva no organismo}

Questionou-se sobre como interpretam a ação do remédio, tanto da farmácia quanto do mato no organismo:

NC - curandeiro, 46 anos: "(a erva agindo no organismo) é que nem o remédio que a gente toma da farmácia né, vai pro organismo, vai pra cabeça, por todo o corpo da gente. pro sangue né então ele penetra . penetra todo o corpo da gente o remédio do mato é que nem o remédio da farmácia".

EC - pedagoga, 50 anos: "é assim, depende muito da reação do teu organismo, se teu organismo agir junto com o medicamento que você toma do mato das ervas medicinais . aí dá certo o efeito . e daí aqueles que não sararam é porque o organismo não ajuda né . tem um que às vezes prejudica né".

(sobre quando você faz um chá, no que você acredita que acontece a cura? Você entende que tem alguma coisa na planta, alguma substância ou algum componente que está dentro da planta ou você acha que tem algum poder que ajuda?) "conforme o organismo da gente reage . se a minha imunidade ajudar . aí vai dar certo né".

JS - posição de destaque na aldeia, 63 anos: "(erva) é mais natural né [...] a gente crê muito em Deus que pra nós Kaingang é o 'Tupen' né . então nós cremos nele que ele já deixou aquela erva que é para aquela dor, aquela doença. então é onde nós, nós imos certinhos (nas plantas) sabendo que é isso e que tem que sarar né . só que nós temos fé também né [...] os antigos, tempos atrás que não existia muita química, os índios só viviam disso, eles sabiam, eles sabem, nós sabemos o básico".

RC - costureira, $\mathbf{5 8}$ anos: "é que o nosso conhecimento da planta . da erva que nós pegamos lá no mato ela tá lá na natureza né . nós sabemos que ela já tem. que ela já é especialmente pra infecção. nós sabemos que ela é pra especialmente pra inflamação da garganta. ela é para dor . então quando você toma um remédio pra infecção ela seja químico né, você sabe que aquela dor já vai aliviar [...] nossos pais nossos avós já diziam esse aqui vai aliviar a dor, esse aqui é pra infecção . então é a mesma coisa que se você tomar a química que se você vai tomar um antibiótico ele é pra infecção né . então dali eu sei se parou a infecção parou a dor né".

Diante das respostas obtidas, observa-se que os entrevistados não souberam expressar como interpretam a ação do remédio do mato no organismo para atuação contra a dor. Mas sabem quais ervas devem coletar para aquele determinado tipo de dor e que irá atuar para amenizá-la. Uns relacionam a fé e a religiosidade, outros a questão de organismos reagirem diferente um do outro, podendo assim explicar um ter a cura mais rápida ou eficiente do que outro.

\section{Plantas medicinais mais citadas entre os entrevistados}

Muitas ervas e cipós foram citadas durante as entrevistas, porém, com nomes na língua Kaingang ou nomes populares. Algumas são fortemente reconhecidas 
na medicina popular, assim, escolheu-se três importantes remédios do mato mais utilizados e citados nas conversas para uma análise mais completa: o pau de andrade (Persea major); o cipó milome (Aristolochia sp.) e cipó escada (Bauhinia sp.) (Quadro 3).

Quadro 3: Informações gerais das plantas medicinais selecionadas

\begin{tabular}{|c|c|c|c|}
\hline $\begin{array}{c}\text { Nome } \\
\text { Popular }\end{array}$ & Família / Nome Científico & $\begin{array}{c}\text { Parte } \\
\text { Utilizada }\end{array}$ & Doença \\
\hline $\begin{array}{c}\text { Pau de } \\
\text { andrade }\end{array}$ & Lauraceae / Persea major & casca & $\begin{array}{c}\text { distúrbios } \\
\text { gástricos } \\
\text { feridas }\end{array}$ \\
\hline $\begin{array}{c}\text { Cipó } \\
\text { milome }\end{array}$ & $\begin{array}{c}\text { Aristolochiaceae / } \\
\text { Aristolochia sp. }\end{array}$ & $\begin{array}{c}\text { casca, } \\
\text { caule e raiz }\end{array}$ & $\begin{array}{c}\text { aumatoide } \\
\text { reutros } \\
\text { outros }\end{array}$ \\
\hline $\begin{array}{c}\text { Cipó } \\
\text { escada }\end{array}$ & Fabaceae / Bauhinia sp. & $\begin{array}{c}\text { casca, } \\
\text { folhas }\end{array}$ & $\begin{array}{c}\text { dores de } \\
\text { coluna }\end{array}$ \\
\hline
\end{tabular}

Conforme Giraldi e Hanazaki (2010), a validação científica para uma eficácia terapêutica de medicamentos tradicionais e a concordância quanto ao seu uso numa comunidade, podem explicar sobre o fato de algumas espécies serem mais citadas nas farmacopeias populares, sendo os três remédios selecionados muito conhecidos e utilizados pelas pessoas do Estado do Paraná. A seguir, alguns trechos da entrevista em que é mencionado o pau de andrade (Persea major) para uso medicinal:

JS - posição de destaque na aldeia, 63 anos: "o remédio pau de andrade [...] ele é bom pra tudo a casca dele. é uma madeira da grossura de pinheiro . e também remédio pro rim, nós também tem que tomar porque tem o remédio que [...] derruba as pedras, só que a gente tem que manter a dieta [...] pra diabetes eu tomava direto né (remédio do mato) e eu sarei, fiz exame não tenho nada . tomei direto chá [garrafada, dia e noite só remédio de ervas]".

RC - costureira, $\mathbf{5 8}$ anos: "tem a casca de andrade que é bom pra ferida cancerosa . pra você tomar se você tem câncer . as ferida ruim né assim".

NC - curandeiro, 46 anos: "nós tomamos remédio que o finado meu pai ele me mostrava remédio né, então tem um remédio que dá a árvore assim por nome andrado, daí a senhora corta aquela casca no tempo da lua nova ela sai um cascão assim .é uma madeira assim . e a gente toma ela, pra não criar ferida . daí não dá ferida [...] "o andrado [...] eu tava em Rio Grande (do Sul) e de repente me ligaram lá de == um casal lá me ligaram se eu não tinha o andrado, daí eu disse tem na [reserva indígena]. eu vim de lá buscar aqui [...] o homem passava com aquela doença (2.0) câncer. e de repente ele tomou e ali passado dois meses, dois meses e pouquinho ele me ligou que disse que não tinha mais câncer. daí esse eu sei que cura câncer né . não tando muito com certeza avançado . então 
ele cura".

Os entrevistados contam que fazem o chá da casca do pau de andrade para doenças relacionadas aos rins e feridas, identificando sua eficácia até mesmo para tumores malignos. A árvore Persea major pertence à família Lauraceae é conhecida popularmente como pau de andrade, pau andrade, abacateiro do mato ou maçaranduba, sendo uma planta medicinal nativa do Sul do Brasil. Possui os seguintes sinônimos científicos: Persea pyrifiolia var. B Nees; P. pyrifolia var. B major Meissner; P. cordata var. major (Meissner) Mez; P. cordata var. pubescens Glaz. e P. tranninensis Glaz. nom. nun. (MARANHO, 1998). Segundo Zeni et al. (2017), o seu uso é restrito às comunidades tradicionais, sendo característica a sua utilização por indígenas que detêm o conhecimento empírico do consumo da casca, que é utilizada para infusão que é administrada por via oral ou tópica para o tratamento de distúrbios gástricos, úlceras e feridas. Assim sendo, pesquisas (SOMENSI et al., 2017; MARANHO; PREUSSLER; ROCHA, 2009) vêm sendo realizadas com objetivo de validação do uso popular do pau de andrade para os estes distúrbios ulcerativos do sistema gastrointestinal e efeito cicatrizante de feridas.

Para a ação gastroprotetora e cicatrizante gástrica, pesquisas como Assis et al. (2003), Somensi et at. (2017) e Cosmo et al. (2007) relatam a atividade citoprotetora do extrato hidroalcoólico de casas de P. major contra lesões gástricas induzidas por etanol. Os resultados apresentaram contribuições significativas para a validação do uso popular de P. major no tratamento de úlceras gástricas, demonstrando a espécie possuir atividade analgésica e gastroprotetora, com alguns componentes quimicos identificados como aminoácidos, ácidos graxos, esteróides, taninos condensados e triperpenos (POTRICH et al, 2014). Porém, mais estudos devem ser realizados para identificar os prováveis mecanismos de ação envolvidos no efeito gastrocinético que o extrato da planta apresenta.

Sobre o uso para cicatrização de ferimentos, Schlemper, Schlemper e Zampirolo (2013) constataram o efeito antiedematogênico, ou seja, agente antiinflamatório e cicatrizante para a pele, ao realizar estudos com roedores. Sieben (2012), Mello (2003), Maranho; Nakashima; Alquini (2001) e Zeni et al. (2017) analisaram a ação da P. major em manejo de feridas de equinos e constataram que a casca possui alto caráter de mucilagem (substância gelatinosa de estrutura complexa, que reage com a água, aumentando de volume e formando uma 
solução viscosa; que retém água). Portanto, na presença de água, as mucilagens incham e tomam um aspecto de gel, agindo de forma protetora das mucosas com inflamações e aliviando as dores. Deste modo, a mucilagem obtida com o uso de pau de andrade em feridas expostas apresentou evolução do processo cicatricial, indicando ser eficiente para a cicatrização de feridas em equinos.

Assim sendo, o pau de andrade possui ações benéficas a tratamentos gástricos e de cicatrização de pele, porém, faltam estudos mais aprofundados que apresentem resultados científicos para ações diretas contra doenças cancerígenas, o qual foi relatado pelos entrevistados como uma eficácia da ingestão da infusão da casca da árvore.

O cipó "de mil homens", que com a pronúncia popular acabou se tornando apenas "milome", também foi citado por diferentes entrevistados:

MS - curandeira, 81 anos: "eu sei tudo quanto é remédio, meu filho sabe tudo quanto é remédio . ele que pega pra $\mathrm{mim}$, remédio do mato pra $\mathrm{mim}==$ pariparova [...] esse aí nós bebemos direto, milome (cipó), tudo quanto é remédio da lavoura nós planta o remédio".

MA - curandeira, 71 anos: "se eu tiver com uma dor, eu tomo chá de milome, faço chá de milome [...] dali a pouco tava bão p ir pro mato".

JS - posição de destaque na aldeia, 63 anos: "o cipó milome também ele é bom pra várias coisas né . pra várias outras doenças".

O cipó milome (Aristolochia sp.) pertence à família Aristolochiaceae, é nativo do Brasil e apresenta aproximadamente sessenta espécies distintas, sendo as mais conhecidas: A. cymbifera, A. triangulares, A. trilobata L. e A. esperanzae, com características e propriedades semelhantes. O cipó apresenta-se como trepadeira herbácea, de ramos finos com o caule engrossado (OLIVEIRA, 2006). Estudos (PACHECO et al., 2010; TORO, 2005) indicam que o uso deste cipó é voltado para tratamentos de artrite reumatoide e diversas outras doenças, como afecções gástricas, indigestão e úlceras crônicas, tendo ampla aplicação na medicina tradicional brasileira e de outros países da América latina. De acordo com Oliveira (2006) e Stasi; Hiruma-Lima (2002), o gênero Aristolochia é composto principalmente de plantas aromáticas, apresentando componentes químicos como allantoina, lignanas, diterpenos, sesquiterpenos e sitostero. Análises (LORENZI; MATOS, 2002) de raízes e caules têm demonstrado presença de diterpenos e sesquiterpenoides ${ }^{10}$ nas

10 Terpenos ou terpenoides são a maior classe química de ativos vegetais. Pertencem a uma vasta classe de metabólitos secundários. 
folhas.

Alguns problemas mais sérios à saúde podem ocorrer quando existe o consumo em excesso de plantas medicinais que contenham substâncias tóxicas, e este é o caso do cipó milome. Determinados países proíbem a comercialização de ervas medicinais que contêm extratos de espécies do gênero Aristolochia, pois esta apresenta em sua composição o ácido aristolóquico (Figura 1), que possui potencial carcinogênico e mutagênico, que em humanos pode levar tanto à problemas crônicos nos rins (nefropatia) quanto ao câncer urotelial (GIRALDl; HANAZAKI, 2010).

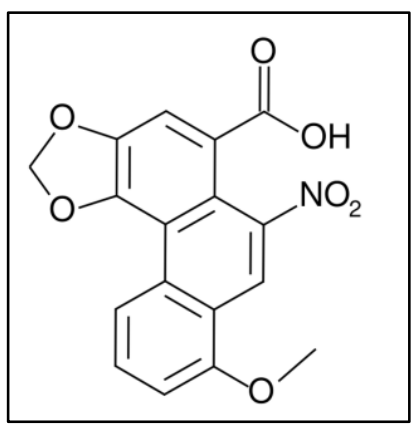

Figura 1: Ácido aristolóquico (Fonte: autoria própria)

Estudos (POON et al., 2013; PING-CHUNG; YUE-CHIUN; TIAN-SHUNG, 2012) revelam que o ácido aristolóquico ocasiona mais mutações do que o tabaco e a luz UV, conhecidos carcinógenos ambientais. São recentes as pesquisas que revelam carcinomas resultantes do seu consumo, e até a agência federal americana "Food and Drug Administration" (FDA) reguladora de medicamentos e alimentos fez um alerta aos consumidores sobre produtos que contêm ácidos aristolóquicos (PLANFAVI, 2013). Em suma, muitas pessoas utilizam o chá de milome com frequência, assim como os indígenas da Reserva visitada. Mas, como visto em investigações científicas o consumo em excesso pode ser nocivo para a saúde.

O terceiro remédio selecionado é o cipó escada (Bauhinia sp.):

JS - posição de destaque na aldeia, $\mathbf{6 3}$ anos: "o cipó escada ele serve mais pra coluna".

RC - costureira, $\mathbf{5 8}$ anos: "tem o cipó milome, tem o cipó de escada para a coluna [...] nós tomamos ainda, no chimarrão . aí quando a gente tá com muita dor nós fazemos pra nós tomar [...] hoje já os mais novos não usam mais [...]".

EC - pedagoga, 50 anos: "tem o cipó escada que é pra coluna né [...] quando destronca né assim ou quebra que eles engessam é assim".

O cipó escada (Bauhinia sp.) é uma planta abundante na mata atlântica 
em diversas regiões do Brasil, conhecida também como escada-de-jabuti ou escada-de-macaco, devido ao cipó possuir forma similar à de uma escada. Devido ao formato de suas folhas, semelhante a uma "pata de vaca", também é chamado popularmente de pata-de-vaca ou unha-de-boi. É amplamente utilizada na medicina popular em forma de infusões ou preparações fitoterápicas para o tratamento de várias enfermidades, principalmente infecções, processos dolorosos e diabetes (FILHO, 2000; SILVA; FILHO, 2002). De acordo com Nogueira e Sabino (2012), o gênero Bauhinia pertence à família Fabaceae, que inclui cerca de 650 gêneros e 18000 espécies distribuídas pelo mundo, porém, existem espécies que são nativas do Brasil, como a B. longifolia e a B. forficata.

Extratos do gênero Bauhinia são amplamente utilizados na medicina popular brasileira, principalmente no controle da glicemia, e outras aplicações como antiinflamatório e analgésico. Nas entrevistas, pode-se observar que os indígenas utilizam o cipó escada para dores na coluna, indicando ser um bom remédio analgésico e anti-inflamatório. Portanto, para a atividade analgésica, investigações (ALEX; JOGHEE, 2020; GUPTA et al., 2005; SILVA, 2014) que analisaram a casca do caule de espécies de Bauhinia, constataram resultados que demonstram alto potencial da planta em produzir um analgésico de ação central. Para a atividade anti-inflamatória, os resultados sugerem efetividade quando comparada ao medicamento padrão Indometacina (medicamento antiinflamatório indicado para o tratamento de artrites reumatoides, osteoporose, dor muscular, tendinite). Em síntese, a planta possui ações farmacológicas que incluem atividades antimicrobianas, anti-helmínticas, antitumorais, antidiabéticas e anti-histamínicas, apresentando potencial terapêutico completo, e assim, de acordo com Alex e Joghee (2020) deve ser mais pesquisado, havendo mais investigações de compostos isolados que possam contribuir para os avanços científicos de que possam beneficiar a humanidade.

\section{Considerações finais}

De acordo com Lappe e Laroque (2015), mesmo que atualmente vivam em áreas urbanas, os Kaingang interagem ativamente com a natureza, seguindo a lógica de sua cultura, o que pode ser confirmado através destas entrevistas realizadas na pesquisa de campo. Segundo Lévi-Strauss (1989), os indígenas possuem um acentuado senso sobre associações vegetais, sendo capazes de 
enumerar nos mínimos detalhes e sem nenhuma hesitação características próprias de diferentes matérias-primas. Essa percepção de Strauss sobre o conhecimento que os indígenas possuem sobre as ervas pode exemplificar o modo como esse saber indígena permanece ainda nos dias de hoje. Gadgil, Berkes e Folke (1993) definiram o conhecimento indígena como transmissão cultural existente sobre as relações entre os seres vivos e o seu ambiente, transmissão essa que ocorre de geração em geração na comunidade. Isso pôde ser identificado na fala dos indígenas entrevistados, mostrando-se forte ainda na cultura Kaingang essa transmissão de costumes, crenças e conhecimentos.

Portanto, por meio das entrevistas e da pesquisa de campo observou-se as relações existentes em uma comunidade Kaingang, respeitando cada indivíduo entrevistado em relação as suas atividades e experiências com o mundo natural e espiritual, acatando suas crenças que envolvem a natureza, o sobrenatural e a organização social em que se apresentam, caracterizando assim o conhecimento tradicional. O status de etnociência, ou seja, o uso do reforço da ciência, como por exemplo, trazido por pesquisas científicas que corroboram com resultados que indicam o porquê dos efeitos positivos de certas ervas e plantas na cura de determinadas doenças, mostram como o saber tradicional é importante e deve ser estudado, mesmo que existam conflitos e incompatibilidade, como no caso das crenças associadas a poderes sobrenaturais e incorporações.

Assim, a investigação da abordagem histórica do conhecimento tradicional Kaingang e as suas interações ao longo do tempo com o senso comum e o conhecimento científico mostram que o saber sobre a planta ou erva que "cura a doença" é resultado das etnopráticas que são repassadas de geração em geração, dando continuidade à etnociência Kaingang, caracterizando assim propriedade intelectual do grupo étnico.

\section{Referências}

ALEX, A. M.; JOGHEE, S. Phytochemistry and Therapeutic potential of Bauhinia racemosa Lam. - A Concise Review. International Journal of Research in Pharmaceutical Sciences, v. 11, n. 1, p. $1045-1050,2020$.

ANDRADE, E. J. Sistema médico Kaingang: Conhecimentos e utilização de "remédios do mato" na Terra Indígena Apucarana. Primeiros Estudos, n. 5, p. 75 85, 2013.

ASSIS, L. N. S. P.; VOSGUERAU, M. C.; BORNATO, F.; CORSO, C. F; CINTRA, T.; COSMO, 
S. A.; MARANHO, L. T.; NOWACKI, L. C. Avaliação da ação analgésica e antiedematogênica do extrato bruto de Persea major. In: CONGRESSO BRASILEIRO DE FARMACOLOGIA E TERAPÊUTICA EXPERIMENTAL, 35, 2003, Águas de Lindóia. Anais... Águas de Lindóia: SBFTE, 2003.

AZEVEDO, V.; CARVALHO, M.; FERNANDES-COSTA, F.; MESQUITA, S.; SOARES, J.; TEIXEIRA, F.; MAIA, A. Transcrever entrevistas: questões conceptuais, orientações práticas e desafios. Revista de Enfermagem Referência, Série IV, n. 14, p. 159 - 168, 2017.

BARDIN, L. Análise de conteúdo. Lisboa: Edições 70, 1977.

COSMO, S. A.; MAYER, B.; FREITAS, C. S.; BAGGIO, C. H.; MARQUES, M. C. A. Gastroprotective effect of hydroalcoholic extract from barks of Persea major Kopp (Lauraceae) in rats. Rev. Bras. Farmacogn. vol. 17, n. 4, 533 - 537, 2007.

CUNHA, M. C. Relações e dissensões entre saberes tradicionais e saber científico. In: Cultura com aspas. São Paulo: Cosac Naify, p. 301 - 310, 2009.

FILHO, V. C. Principais avanços e perspectivas na área de produtos naturais ativos: estudos desenvolvidos no NIQFAR/UNIVALI. Química Nova, v. 23, n. 5, p. 680 - 685, 2000.

FONSECA, J. S. Metodologia da pesquisa científica. Universidade Estadual do Ceará. Fortaleza, 2002.

GADGIL, M.; BERKES, F.; FOLKE, C. Indigenous Knowledge for biodiversity conservation. Ambio, v. 22, n. 2-3, p. 151 - 156, 1993.

GAUDÊNCIO, J. S.; MARTINS, D. R.; SILVEIRA, R. M. C. F.; RODRIGUES, S. P. J. Breve perspectiva historiográfica sobre a ancestralidade da etnia indígena Kaingang. Cadernos do CEOM, v. 32, p. $104-117,2019$.

GAUDÊNCIO, J. S.; RODRIGUES, S. P. J.; SILVEIRA, R. M. C. F.; MARTINS, D. R. Etnociência Kaingang: uma revisão sistemática de literatura. Cadernos do CEOM, v. 33, n. 53, p. $157-171,2020$.

GIRALDI, M.; HANAZAKI, N. Uso e conhecimento tradicional de plantas medicinais no Sertão do Ribeirão, Florianópolis, SC, Brasil. Acta bot. bras., vol. 24, n. 2, p. 395 406, 2010.

GUPTA, M.; MAZUMDER, U. K.; KUMAR, R. S.; GOMATHI, P.; RAJESHWAR, Y.; KAKOTI, B. B.; SELVEN, V. T. Anti-inflammatory, analgesic, and antipyretic effects of methanol extract from Bauhinia racemosa stem bark in animal models. Journal of Ethnopharmacology, vol. 98, p. $267-$ 273, 2005.

LAPPE, E.; LAROQUE, L. D. Indígenas e Natureza: a reciprocidade entre os Kaingang e a natureza nas Terras Indígenas Por Fi Gâ, Jamã Tÿ Tãnh e Foxá. Desenvolvimento e Meio Ambiente, vol. 34, p. 147 - 156, 2015.

LÉVI-STRAUSS, C. O Pensamento Selvagem. Campinas: Papirus, 1989.

LORENZI, H; MATOS, F.J.A. Plantas Medicinais no Brasil: nativas e exóticas. Nova 
MARANHO, L. T.; NAKASHIMA, T.; ALQUINI, Y. Estudo anatômico das folhas de Persea major Kopp. Lauraceae. Revista Brasileira de Farmácia, vol. 82, n.1/2, p. 57 - 61, 2001.

MARANHO, L. T. (1998). Contribuição ao estudo botânico, fitoquímico, farmacológico e microbiológico de Persea major (Meisn.) L. E. Kopp (Lauraceae). 85 p. Dissertação. Mestrado em Botânica, Universidade Federal do Paraná, Curitiba, 1998.

MARANHO, L. T; PREUSSLER, K. H.; ROCHA, L. D. Organização estrutural da casca de Persea major Kopp (Lauraceae). Acta bot. bras., vol. 23, n. 2, p. 509 - 515, 2009.

MELLO, R. A. Atividade antimicrobiana do extrato bruto da casca de Persea major (Meisn.) L. E. Kopp (LAURACEAE). In: VII Seminário de Pesquisa - pesquisa e promoção humana. Universidade Tuiuti do Paraná, Curitiba, 2003.

MOREIRA, H.; CALEFFE, L. G. Metodologia da pesquisa para o professor pesquisador. Rio de Janeiro: Lamparina, 2008.

MYERS, G. Análise da conservação e da fala. In: BAUER, M. W.; GASKELL, G. (Ed.). Pesquisa qualitativa com texto, imagem e som: um manual prático. Rio de Janeiro: Vozes, Cáp. 11, p. 271, 2002.

NOGUEIRA, A. C. O.; SABINO, C. V. S. Revisão do gênero Bauhinia abordando aspectos científicos das espécies Bauhinia forficata Link e Bauhinia variegata L. de interesse para a indústria farmacêutica. Revista Fitos, v. 7, n. 2, p. $77-84,2012$.

OLIVEIRA, D. G. Características sócio-demográficas e epidemiológicas da tuberculose: avaliação etnobotânica e da atividade antimicobacteriana das plantas utilizadas por uma comunidade indígena. 2006. Tese. (Doutorado em Análises Clínicas) - Universidade Estadual Paulista, UNESP, 2006.

PACHECO, A. G.; SILVA, T. M.; MANFRINI, R. M.; SALLUM, W. S. T.; DUARTE, L. P.; PILÓVELOSO, D.; ALCÂNTARA, A: F. C. Estudo químico e atividade antibacteriana do caule de Aristolochia esperanzae Kuntze (ARISTOLOCHIACEAE). Química Nova, v. 33, n. 8, p. $1649-1652,2010$.

PING-CHUNG, K.; YUE-CHIUN, L.; TIAN-SHUNG, W. Chemical constituents and pharmacology of the Aristolochia species. J. Tradit. Complement. Med., v. 2, p. 249 $-266,2012$.

PLANFAVI. Boletim. Ricardo Tabach. Sistema de farmacovigilância em plantas medicinais. julho/setembro, 2013. CEBRID, UNIFESP, n. 27. Disponível em: https://www.cebrid.com.br/wp-content/uploads/2014/10/Boletim-PLANFAVI-27Julho-Agosto-Setembro-2013.pdf

POON, S. L.; SEE-TONG, P.; JOHN, R. M.; WILLIE, Y.; KIE, K. H.; PEIYONG, G.; WEN-HUI, W.; EE, Y. S.; YUJING, L.; HONG, L. F.; SOO, C. C.; ANNA, G.; SU, T. T.; WENG, K. L.; IOANA, C.; DACHUAN, H.; LIAN, D. L.; MAARJA-LIIS, N.; MING, H. L.; YING-HSU, C.; KAI-JIE, Y.; WARAPORN, C.; BIN-KUI, L.; YUN-FEI, Y.; CHAO-NAN, Q.; KWAI-FONG, N.; CHING-FANG, W.; CHENG-LUNG, H.; RALPH, M. B; MICHAEL, R. S.; P ANDREW, 
F.; WING-KIN, S.; CHENG-KENG, C.; CHOON, K. O.; STEVEN, G. R.; PATRICK, T.; BIN, T. T. Genome-Wide Mutational Signatures of Aristolochic Acid and Its Application as a Screening Tool. Science Translational Medicine, v. 5, n. 197, p. 1 - 10, 2013.

POTRICH, F. B.; BAGGIO, C. H.; FREITAS, C. S.; MAYER, B.; SANTOS, A. C.; TWARDOWSCHY, A.; GUEDES, A.; MARQUES, M. C. A. Ação de extratos de plantas medicinais sobre a motilidade do trato gastrointestinal. Rev. Bras. Pl. Med., vol.16, n.3, supl. I, p. $750-754,2014$.

REIS, D. A. As práticas de autocuidado e o cuidado familiar dos índios Mura de Autazes, Amazonas. 2016. Tese (Doutorado em Enfermagem na Saúde do Adulto) - Universidade de São Paulo/USP. São Paulo, 2016.

SCHLEMPER, V.; SCHLEMPER, S. R. M.; ZAMPIROLO, J. A. Antiedematogenic effects of the polar fractions of Persea cordata Mez. (Lauraceae) on microvascular extravasation in rat skin. Journal of Ethnopharmacology, vol. 150, p. $244-251,2013$.

SIEBEN, P. G. Composição fitoquímica de cascas de Persea major (MEISN.) L.E. KOPP (LAURACEAE), desenvolvimento e avaliação preliminar de formas farmacêuticas para uso tópico. (2021). Dissertação. Mestrado em Ciências Farmacêuticas, Universidade Federal do Paraná (UFPR), 2012.

SILVA, C. A. M. Estudo químico biomonitorado de extratos das folhas de Bauhinia variegata var. variegata DC. para a identificação de agonista do Receptor Ativado por Proliferadores Peroxissomais - gama (PPARY). (2014). Tese. Doutorado em Ciências da Saúde, Universidade de Brasília, 2014.

SILVA, K. L.; FILHO, V. C. Plantas do gênero Bauhinia: composição química e potencial farmacológico. Química Nova, v. 25, n. 3, p. 449 - 454, 2002.

SOMENSI, L. B.; BOEING, T.; CURY, B. J.; STEIMBACH, V. M. B.; NIERO, R.; DE SOUZA, L. M.; DA SILVA, L. M.; DE ANDRADE, S. F. Hydroalcoholic extract from bark of Persea major (Meisn.) L.E. Kopp (Lauraceae) exerts antiulcer effects in rodents by the strengthening of the gastric protective factors. Journal of Ethnopharmacology, $v$. 209 , p. $294-304,2017$.

STASI, L. C.; HIRUMA-LIMA, C. A. Plantas medicinais na Amazônia e na Mata Atlântica. São Paulo: Editora UNESP, 2002.

TORO, O. A. El uso de hierbas medicinales puede producir graves problemas nefrológicos y urológicos. Actas Urológicas Españolas, v. 29, n. 8, p. 801 - 802, 2005.

ZENI, L. C.; LARA, P.; SOUSA, E. L.; MICHELOTTO JR., P. V.; CABRAL., L. D. R. Utilização do Persea major (pau-de-andrade) em ferida de equino. Rev. Acad. Ciênc. Anim., vol. 15 (Supl.1), p. $417-418,2017$. 